\title{
Calculation of the ratio of the mononucleosome mapping number to the dinucleosome mapping number for each nucleotide position in the Aspergillus fumigatus genome
}

\author{
This article was published in the following Dove Press journal: \\ Open Access Bioinformatics \\ 6 November 2009 \\ Number of times this article has been viewed
}

\author{
Hiromi Nishida \\ Agricultural Bioinformatics Research \\ Unit, Graduate School of Agricultural \\ and Life Sciences, University of Tokyo, \\ Tokyo, Japan
}

\begin{abstract}
The ratio of the mononucleosome mapping site-number to the dinucleosome mapping site-number calculated using nucleosome mapping data of Aspergillus fumigatus was employed as a marker for the sensitivity of nucleosomes to micrococcal nuclease (MNase). This ratio was obtained for four different regions, namely, active gene bodies, active gene promoters, inactive gene bodies, and inactive gene promoters and compared. It was found that the nucleosomes located in the active gene promoters were more sensitive to MNase than those in the active gene bodies but less sensitive than those in the inactive gene bodies and promoters. In addition, compared to the gene bodies, gene promoters have a greater variety of nucleosomes that are sensitive to MNase, regardless of the transcriptional activity of these genes. This study showed that in addition to a mononucleosome map, a dinucleosome map is useful for estimating the sensitivity of nucleosomes to MNase.
\end{abstract}

Keywords: Aspergillus fumigatus, chromatin, dinucleosome stability, micrococcal nuclease sensitivity, nucleosome, transcriptional activity

\section{Introduction}

Eukaryotic genomic DNA is packaged with histones to form chromatin, ${ }^{1}$ in which the most fundamental repeating unit is the nucleosome. ${ }^{2}$ Nucleosomes consist of an octamer of histones around which genomic DNA is wrapped. ${ }^{2}$ Adjacent nucleosomes are separated by unwrapped linker DNA. Analyses performed using genomic tiling arrays or massively parallel DNA sequencers have led to the high-resolution mapping of nucleosome positions. ${ }^{3-13}$ The genome-wide nucleosome map has revealed the relationship between nucleosome density (particularly, the presence or absence of nucleosomes in gene promoter regions) and gene expression.

In the genome of the filamentous fungus Aspergillus fumigatus, 7,715,001 mononucleosomal and 8,565,279 dinucleosomal DNA fragments have already been sequenced and mapped using a massively parallel DNA sequencer. ${ }^{13}$ In a previous study, a relationship was shown to exist between the distribution of nucleosomal DNA fragment lengths and gene expression levels. The distribution of mononucleosomal DNA fragment lengths showed two peaks: one at $135 \mathrm{nt}$ and the other at $150 \mathrm{nt} .{ }^{13}$ The gene bodies of active and inactive genes and inactive gene promoters showed these two peaks; however, the peak produced at $150 \mathrm{nt}$ by the active gene promoters was lost. ${ }^{13}$ This may be because the active promoters were more sensitive to micrococcal nuclease (MNase) than the other regions and therefore may have lost the farther peak.
Agricultural Bioinformatics Research Unit, Graduate School of Agricultural and Life Sciences, University of Tokyo, I - I-I Yayoi, Bunkyo-ku, Tokyo II 3-8657, Japan

Tel $+8|3584| \quad \mid 297$

Fax +8I $3584 I 1136$

Email hnishida@iu.a.u-tokyo.ac.jp 
In order to ascertain this assumption, sensitivity to MNase should be examined.

Genomic DNA consists of regions with varied sensitivity to MNase. ${ }^{14-16}$ MNase digests unwrapped linker DNA but does not digest nucleosome-bound DNA. Prolonged treatment with MNase (eg, a 15-min treatment of rye chromatin with MNase) results in nearly complete cleavage of the total DNA into mononucleosomes; ${ }^{16}$ this finding suggests that MNase-digested dinucleosomes are precursors of mononucleosomes. Assuming that $A$. fumigatus dinucleosomes function as mononucleosome precursors, it may be possible to use the ratio of the mononucleosome mapping site-number to the dinucleosome mapping site-number as a marker for sensitivity of nucleosomes to MNase or dinucleosome stability. By comparing the ratios obtained in four regions, namely, active gene bodies, active gene promoters, inactive gene bodies, and inactive gene promoters, the sensitivity of the nucleosomes to MNase or the stability of dinucleosomes can be estimated.

\section{Methods}

On the basis of each nucleosomal DNA fragment sequence obtained from mononucleosome and dinucleosome mapping data in A. fumigatus, ${ }^{13}$ mononucleosome and dinucleosome mapping numbers were estimated for each nucleotide position in the region from $1 \mathrm{~kb}$ upstream of the translational start site to the translational end site of a gene (Figure 1). Next, the ratio of the mononucleosome mapping number to the dinucleosome mapping number was calculated for each nucleotide. In this study, 50 genes with the highest expression levels (excluding rRNA genes) and 50 genes with the lowest expression levels were analyzed; the genes were selected on the basis of microarray data obtained in a previous study. ${ }^{13}$ The gene promoter was defined as the region from $1 \mathrm{~kb}$ upstream of the translational start site, and the gene body was defined as the region from the translational start site to the translational end site.

\section{Results and discussion}

The mononucleosome and dinucleosome mapping numbers and their ratio were calculated for each nucleotide position in the region from $1 \mathrm{~kb}$ upstream of the translational start site to the translational end site of each of the 50 transcriptionally active and 50 transcriptionally inactive genes. The genomic nucleotide positions that exhibited a ratio of the mononucleosome mapping number to the dinucleosome mapping number with both numbers being $\geq 1$ for each nucleotide position in the active gene bodies, active gene promoters, inactive gene bodies, and inactive gene promoters were $71,873,37,734$, 60,478 , and 42,386 , respectively.

\section{Mapped nucleosomal DNA sequences}

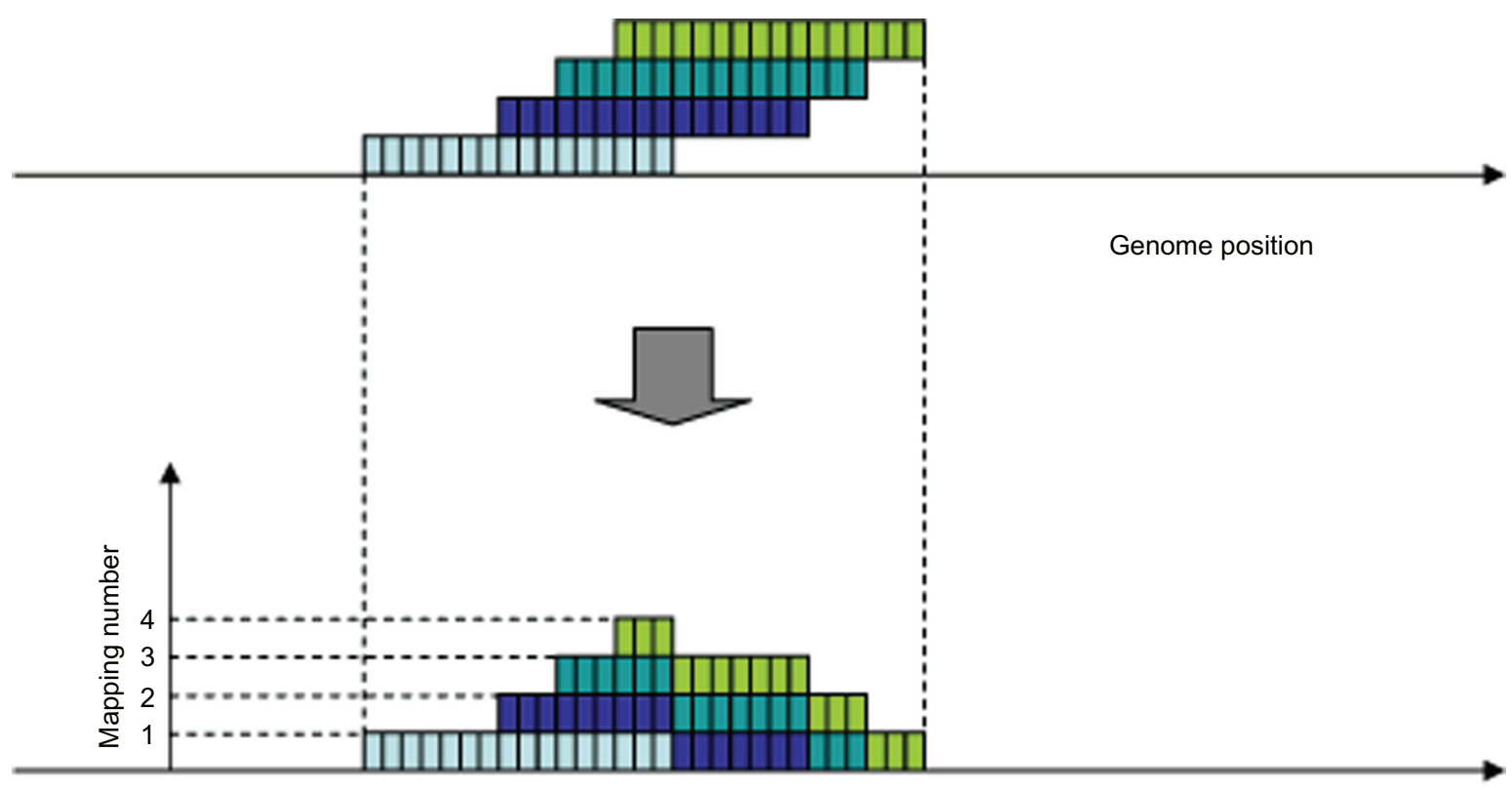

Figure I An example of mapping numbers for each nucleotide position. The four colors indicate the different nucleosomal DNA fragment sequences. Each box represents a genomic nucleotide. In this example, three nucleotide positions are shared by four different sequences (mapping number, 4). 
The genes Afu5g03760 and Afu2g13025 had the highest and lowest expression, respectively, and are shown in Figure 2. Although the dinucleosome mapping numbers were higher than the mononucleosome mapping numbers, the profiles of the two types of numbers were similar. The Spearman's rank correlation coefficients between the mononucleosome mapping numbers and the dinucleosome mapping numbers were 0.68 (the 50 transcriptionally active gene promoters), 0.61 (the 50 transcriptionally active gene bodies), 0.65 (the 50 transcriptionally inactive gene promoters), and 0.71 (the 50 transcriptionally inactive gene bodies). These findings suggest that many of the dinucleosomes served as precursors for the mononucleosomes. If this assumption holds true, genomic regions with a high ratio of the mononucleosome mapping number to the dinucleosome mapping number will be more sensitive to MNase than other regions. In other words, the dinucleosome stability of such regions would be low.

Among the 50 transcriptionally active genes, 22 genes had the region(s) with high ratio ( $>2$ in $\log _{2}$ scale) of the mononucleosome mapping number to the dinucleosome mapping number (Supplementary Data 1, Table 1; see http://www.dovepress.com/submission_7797_files.php for all supplementary data). Among the 50 transcriptionally inactive genes, 27 genes had the region(s) with high ratio $\left(>2\right.$ in $\log _{2}$ scale) of the mononucleosome mapping number to the dinucleosome mapping number (Supplementary Data 2, Table 1). Most of those regions were AT rich, regardless of their transcriptional activation status (Supplementary Data 3 and 4, Table 1). This result is consistent with the yeast nucleosome positioning. ${ }^{17}$

The median values of the ratio $\left(\log _{2}\right.$ scale $)$ of the mononucleosome mapping number to the dinucleosome mapping number in the active gene bodies, active gene promoters, inactive gene bodies, and inactive gene promoters were $-1.37,-1.00,-0.72$, and -0.76 , respectively (Figure 3 ). Comparison of the four median values strongly indicated that the dinucleosomes are more stable in active genes (both promoters and bodies) than in inactive genes.
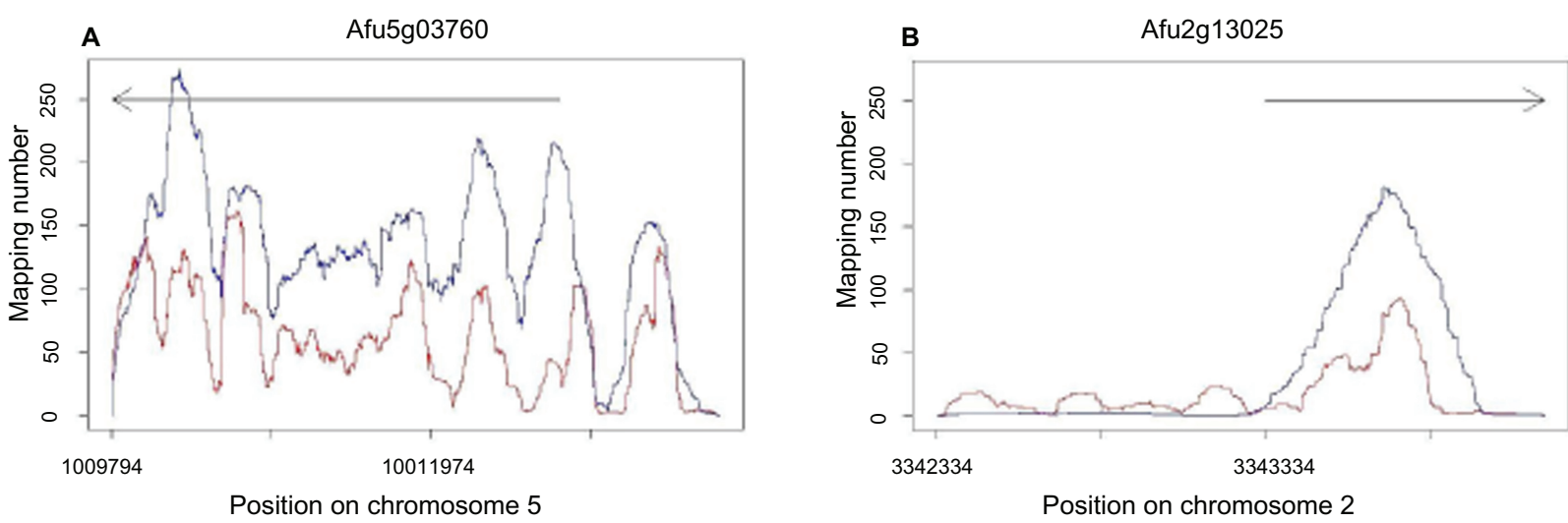

C
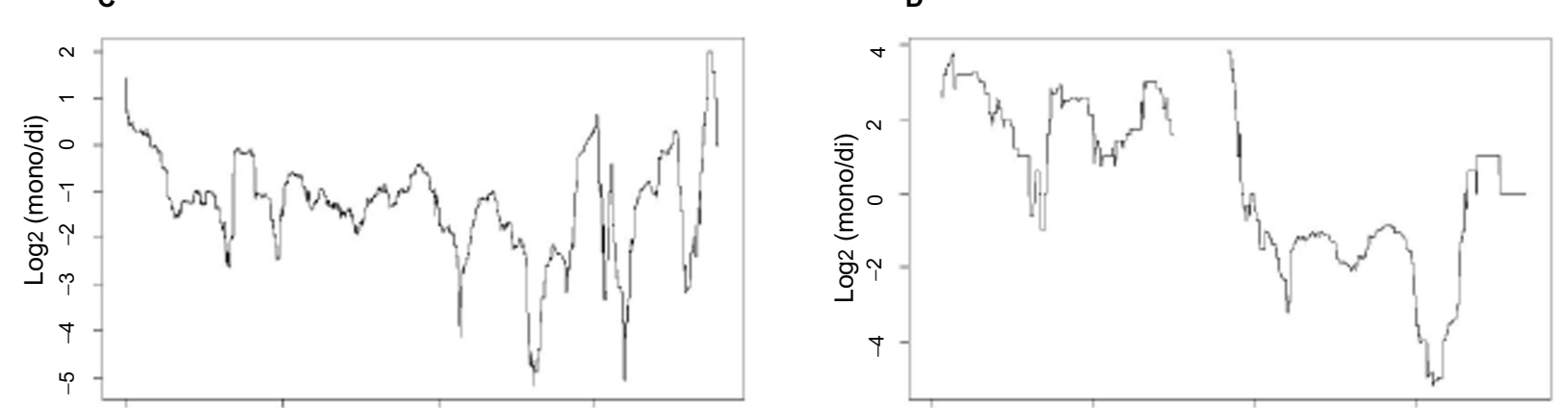

Figure 2 Mapping numbers and ratios of the mononucleosome mapping number to the dinucleosome mapping number for the genes $\mathrm{Afu} 5 \mathrm{~g} 03760$ and $\mathrm{Afu} 2 \mathrm{~g} / 3025$, which had the highest and lowest expression, respectively. A) Red and blue have been used to indicate the mononucleosome and dinucleosome mapping numbers, respectively, in the region from I kb upstream of the translational start to the translational end site in Afu5g03760. The arrow indicates the region from the translational start site to the translational end site. B) Red and blue indicate the mononucleosome and dinucleosome mapping numbers, respectively, in the region from I kb upstream of the translational start site to the translational end site in Afu2g/3025. The arrow indicates the region from the translational start site to the end site. C) Ratio (log scale) of the mononucleosome mapping number to the dinucleosome mapping number for Afu5g03760. D) Ratio ( $\log _{2}$ scale) of the mononucleosome mapping number to the dinucleosome mapping number for Afu2g/3025. 
Table I Genes with high ratio ( $>2$ in $\log _{2}$ scale) of the mononucleosome mapping number to the dinucleosome mapping number

\begin{tabular}{|c|c|c|}
\hline Gene & Region & AT-rich \\
\hline \multicolumn{3}{|c|}{ Transcriptionally active genes (22 genes) } \\
\hline Afu lg02550 & Promoter & No \\
\hline Afu lg03570 & Promoter/Body & Yes/Yes \\
\hline Afu lg03630 & Promoter & Yes \\
\hline Afulg 14220 & Promoter & Yes \\
\hline Afu2gIII50 & Promoter/Body & Yes/No \\
\hline Afu2gII520 & Promoter & Yes \\
\hline Afu2gl3530 & Promoter & No \\
\hline Afu2gl6060 & Promoter & Yes \\
\hline Afu3g080I0 & Promoter & No \\
\hline Afu3g08I60 & Promoter & Yes \\
\hline Afu3g 10660 & Promoter & Yes \\
\hline Afu3g 10960 & Promoter & Yes \\
\hline Afu $4 g 06820$ & Promoter & No \\
\hline Afu $4 g|3| 20$ & Promoter & Yes \\
\hline Afu5g03020 & Promoter & Yes \\
\hline Afu5g04210 & Promoter & Yes \\
\hline Afu5g04230 & Promoter & No \\
\hline Afu5g08830 & Promoter & Yes \\
\hline Afu6g04740 & Promoter & Yes \\
\hline Afu8g03930 & Promoter & Yes \\
\hline Afu8g05320 & Promoter & Yes \\
\hline Afu8g05610 & Promoter & Yes \\
\hline \multicolumn{3}{|c|}{ Transcriptionally inactive genes ( 27 genes) } \\
\hline Afulg00I40 & Body & Yes \\
\hline Afu lg09340 & Promoter/Body & Yes/Yes \\
\hline Afulg 13810 & Body & Yes \\
\hline AfulgI54I0 & Promoter/Body & Yes/Yes \\
\hline AfulgI7300 & Promoter/Body & Yes/Yes \\
\hline Afu2g04I80 & Promoter & Yes \\
\hline Afu2g04420 & Promoter & Yes \\
\hline Afu2g09970 & Promoter/Body & Yes/Yes \\
\hline Afu2gl3025 & Promoter & Yes \\
\hline Afu2gl3300 & Promoter & No \\
\hline Afu2gl7550 & Promoter & Yes \\
\hline Afu3g0I470 & Promoter & Yes \\
\hline Afu3g03270 & Promoter & Yes \\
\hline Afu3gl4580 & Promoter & Yes \\
\hline Afu $4 g 06650$ & Promoter/Body & Yes/Yes \\
\hline Afu $4 g \mid 4530$ & Promoter & No \\
\hline Afu4g|4690 & Promoter & Yes \\
\hline Afu5gl| 060 & Promoter & Yes \\
\hline Afu5g 12690 & Promoter & Yes \\
\hline Afu5gl4100 & Promoter & Yes \\
\hline Afu5g|4840 & Body & Yes \\
\hline Afu5gl4990 & Promoter & Yes \\
\hline Afu6g I I 280 & Promoter & Yes \\
\hline Afu7g04530 & Promoter & No \\
\hline Afu8g00820 & Promoter & Yes \\
\hline Afu8g02230 & Promoter & Yes \\
\hline Afu8g02270 & Promoter & Yes \\
\hline
\end{tabular}

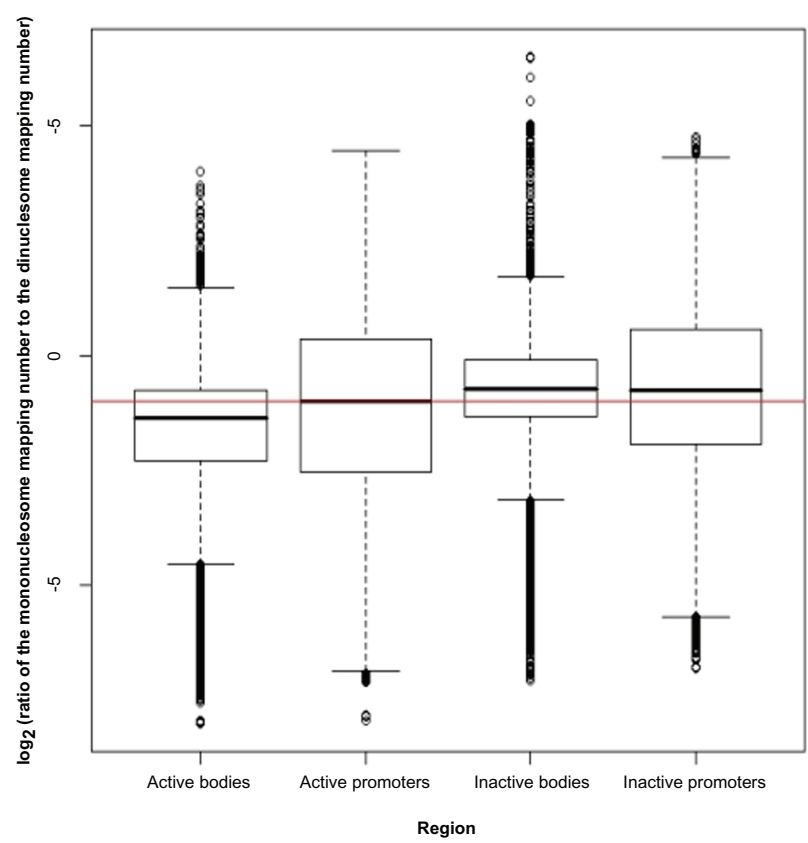

Figure 3 Boxplots of the ratios ( $\log _{2}$ scale) of the mononucleosome mapping number to the dinucleosome mapping number in transcriptionally active and inactive gene bodies and promoters. The boxes are composed of the medians with the first and third quartiles. The dots indicate outliers. The genomic nucleotide positions with a significant ratio of the mononucleosome mapping number to the dinucleosome mapping number (with both numbers being $\geq I$ for a single nucleotide position) in the active gene bodies, active gene promoters, inactive gene bodies, and inactive gene promoters were $71,873,37,734,60,478$, and 42,386 , respectively. The median values for the ratio $\left(\log _{2}\right.$ scale) of the mononucleosome mapping number to the dinucleosome mapping number in the active gene bodies, active gene promoters, inactive gene bodies, and inactive gene promoters were $-1.37,-1.00,-0.72$, and -0.76 , respectively. The red line indicates the median for the ratio $\left(\log _{2}\right.$ scale) of the mononucleosome mapping number to the dinucleosome mapping number in the active gene promoters.

In addition, the difference ( 0.37$)$ between the medians of the ratios for the active gene bodies and promoters was higher than the difference $(0.04)$ between the medians of the ratios for the inactive gene bodies and promoters. Thus, the nucleosomes in the active gene promoters are certainly more sensitive to MNase than the nucleosomes in the active gene bodies but are less sensitive than those in the inactive gene bodies and promoters. This result indicates that the sensitivity of the active promoters to MNase is not the sole reason for the loss of the farther peak in the distribution of the mononucleosomal DNA fragment lengths in the active gene promoters. ${ }^{13}$

The histograms for the ratio $\left(\log _{2}\right.$ scale) of the mononucleosome mapping number to the dinucleosome mapping number in the 4 different regions were compared (Figure 4); it was found that the distributions in the gene bodies (both active and inactive) produced a larger peak than those in the corresponding gene promoters. This indicates that compared to gene bodies, gene promoters have a greater variety of 
Active gene promoters

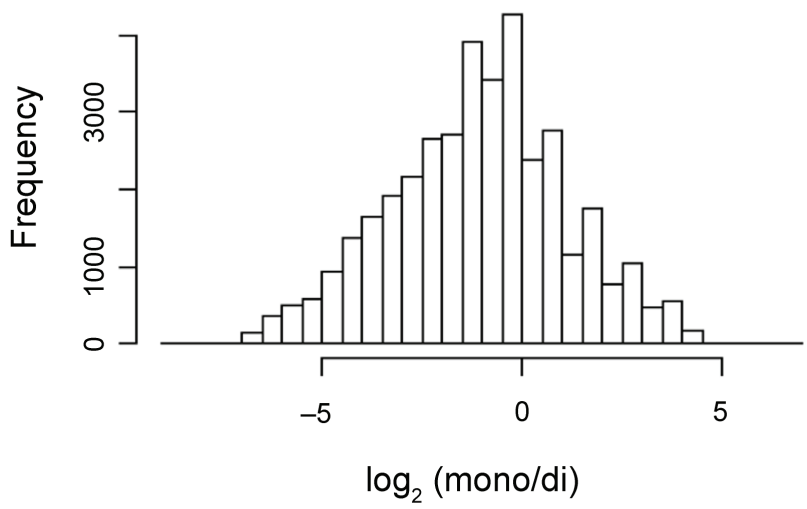

Active gene bodies

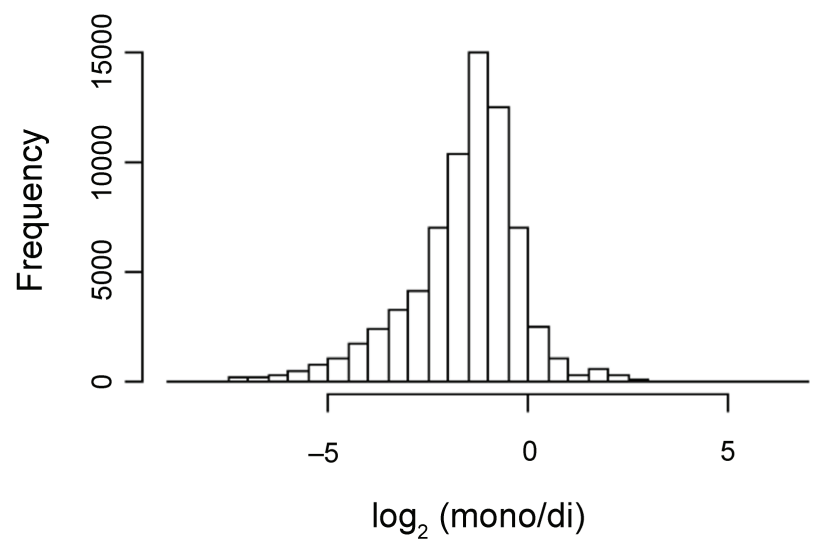

Inactive gene promoters

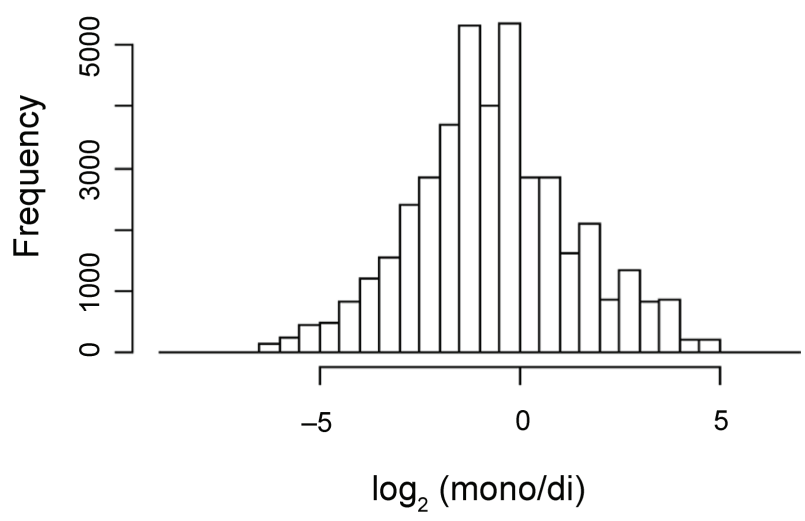

Inactive gene bodies

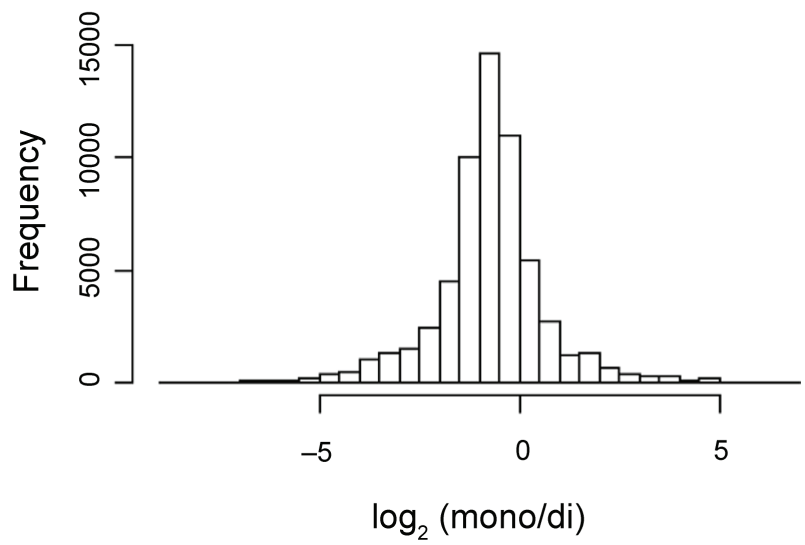

Figure 4 Histograms of the ratio $\left(\log _{2}\right.$ scale) of the mononucleosome mapping number to the dinucleosome mapping number in transcriptionally active and inactive gene bodies and promoters. The genomic nucleotide positions with a significant ratio of the mononucleosome mapping number to the dinucleosome mapping number (with both numbers being $\geq \mathrm{I}$ for a single nucleotide position) in the active gene bodies, active gene promoters, inactive gene bodies, and inactive gene promoters were $7 \mathrm{I}, 873$, $37,734,60,478$, and 42,386 , respectively. The differences of the distributions between the gene promoters and the gene bodies were evaluated by the Kolmogorov-Smirnov test. The results indicated that those differences in both the transcriptionally active and inactive genes were statistically significant $\left(P\right.$-value $\left.<2.2 \times 10^{-16}\right)$.

nucleosomes that are sensitive to MNase, regardless of the transcriptional activity of these genes. It is possible that a variety of modified histones are related to the different types of nucleosomes in gene promoters that are sensitive to MNase. Fungi possess various histone modification systems. ${ }^{18}$ In human cells, the relative nucleosome depletion in the vicinity of the transcription start site may not necessarily be associated with active transcription but with histone modification in gene promoters. ${ }^{19}$ Hence, the sensitivity of nucleosomes to MNase may be related to histone modification, regardless of the transcriptional activity of the genes. Generally the nucleosome map studies are based on the mononucleosome map data. This study showed that in addition to a mononucleosome map, a dinucleosome map is useful for determining the sensitivity of nucleosomes to MNase.

\section{Acknowledgments}

This study was supported by a grant from the Institute for Fermentation, Osaka. The author reports no conflicts of interests in this work.

\section{References}

1. Igo-Kemenes T, Hörz W, Zachau HG. Chromatin. Annu Rev Biochem. 1982;51:89-121.

2. Luger K. Dynamic nucleosome. Chromosome Res. 2006;14:5-16.

3. Dennis JH, Fan HY, Reynold SM, et al. Independent and complementary methods for large-scale structural analysis of mammalian chromatin. Genome Res. 2007;17:928-939.

4. Kaplan N, Moore IK, Fondufe-Mittendorf Y, et al. The DNAencoded nucleosome organization of a eukaryotic genome. Nature. 2009;458:362-366.

5. Lee W, Tillo D, Bray N, et al. A high-resolution atlas of nucleosome occupancy in yeast. Nat Genet. 2007;39:1235-1244.

6. Mavrich TN, Jiang C, Ioshikhes IP, et al. Nucleosome organization in the Drosophila genome. Nature. 2008;453:358-362. 
7. Schones DE, Cui K, Cuddapah $\mathrm{S}$, et al. Dynamic regulation of nucleosome positioning in the human genome. Cell. 2008;132:887-898.

8. Segal E, Fondufe-Mittendorf Y, Chen L, et al. A genomic code for nucleosome positioning. Nature. 2006;442:772-778.

9. Shivaswamy S, Bhinge A, Zhao Y, Jones S, Hirst M, Lyer VR. Dynamic remodeling nucleosomes across a eukaryotic genome in response to transcriptional perturbation. PLoS Biol. 2008;6:e65.

10. Song JS, Liu X, Liu XS, He X. A high-resolution map of nucleosome positioning on a fission yeast centromere. Genome Res. 2008;18: 1064-1072.

11. Valouev A, Ichikawa J, Tonthat T, et al. A high-resolution, nucleosome position map of C. elegans reveals a lack of universal sequence-dictated positioning. Genome Res. 2008;18:1051-1063.

12. Yuan GC, Liu YJ, Dion MF, et al. Genome-scale indentification of nucleosome positions in S. cerevisiae. Science. 2005;309:626-630.

13. Nishida H, Motoyama T, Yamamoto S, Aburatani H, Osada H. Genomewide maps of mono- and di-nucleosomes of Aspergillus fumigatus. Bioinformatics. 2009;25:2295-2297.
14. Henikoff S, Henikoff JG, Sakai A, Loeb GB, Ahmad K. Genome-wide profiling of salt fractions maps physical properties of chromatin. Genome Res. 2009;19:460-469.

15. Tolstorukov MY, Kharchenko PV, Goldman JA, Kingston RE, Park PJ. Comparative analysis of H2A.Z nucleosome organization in the human and yeast genomes. Genome Res. 2009;19:967-977.

16. Vershinin AV, Heslop-Harrison JS. Comparative analysis of the nucleosomal structure of rye, wheat and their relatives. Plant Mol Biol. 1998;36:149-161.

17. Ioshikhes IP, Albert I, Zanton SJ, Pugh BF. Nucleosome positions predicted through comparative genomics. Nat Genet. 2006;38:1210-1215.

18. Nishida H. Evolutionary conservation levels of subunits of histonemodifying protein complexes in fungi. Comp Funct Genomics. 2009;2009:379317.

19. Nishida H, Suzuki T, Kondo S, Miura H, Fujimura Y, Hayashizaki Y. Histone $\mathrm{H} 3$ acetylated at lysine 9 in promoter is associated with low nucleosome density in the vicinity of transcription start site in human cell. Chromosome Res. 2006;14:203-211.

\section{Publish your work in this journal}

Open Access Bioinformatics is an international, peer-reviewed, open access journal publishing original research, reports, reviews and commentaries on all areas of bioinformatics. The manuscript management system is completely online and includes a very quick and fair

\section{Dovepress}

peer-review system. Visit http://www.dovepress.com/testimonials.php to read real quotes from published authors. 